\title{
Concept of an integrated decision- making support and assessment system
}

\author{
J. Petermann, S. Wirth \\ Institute of Industrial Sciences and Factory Systems, Chemnitz \\ University of Technology \\ Technische Universität Chemnitz, D-09107, Germany \\ Tel: ++49-371-531-5318, ++49-371-531-5309 \\ Fax: ++49-371-531-5320, ++49-371-531-5327 \\ e-mail:joachim.petermann@mb2.tu-chemnitz.de, \\ s.wirth@mb2.tu-chemnitz.de
}

\begin{abstract}
Using modelling and simulations in enterprises assists decision-making and allows for transparent and effective judgements. Although contemporary enterprise models make integrated and complex process controlling possible, further strategic aspects in attaining optimal processes are conceivable. Instead of optimising individual targets (e.g., resource optimisation, capacity utilisation, etc.), an approach from the point of view of process quality will be presented here. A promising field offers the inclusion of dynamic resources in enterprise planning and controlling.
\end{abstract}

Keywords

Production system simulation, process optimisation

\section{INTRODUCTION}

Globalisation of the market place, growing surplus production capacity, and potential offers resulting from them are leading to continuously intensifying competition in all fields of production and services. In order to compete successfully, enterprise management must react dynamically to the constantly changing market situation. Furthermore, factory structures and their configuration have to be regularly examined.

Managing these tasks requires continuously developing and assessing alternative solutions so that favourable or optimal decisions can be made. However, it is 
equally important to not only consider the immediate consequences of decisions, rather their long-term consequences as well. The difficulties of realising these tasks is a result of, on one hand, the complexity of the influences and dependency on real enterprise processes and, on the other hand, of the imprecise and unclear prerequisites for decisions in the middle-term.

Enterprise process simulation presents itself as an important aid for coping with these demands. By modelling and simulating the performance of enterprise processes, production processes may be depicted and examined as an interaction between the elementary factors of the product, equipment, and human labour. Varying parameters or process alternatives makes it possible to orient production management successfully into the available scope of decision-making regarding contractual or optimal solutions.

\section{MODELLING AND SIMULATING PRODUCTION SYSTEMS}

Modelling enterprises, including smaller enterprises, and management processes presents a complex network. Modelling value-adding through the production process leads to demanding modelling representations regarding the interaction between production and finance processes. This considerably expands the scope of investigation. Various studies have proved that, with the help of appropriate simulation tools, modelling production processes can lead to good praxis-relevant results. In particular, chronological process sequences in accordance with competing tasks and scarce resources can determine an adequate timeframe with agreement to the real course of the process. Figure 1 shows the results of a simulation investigation. 


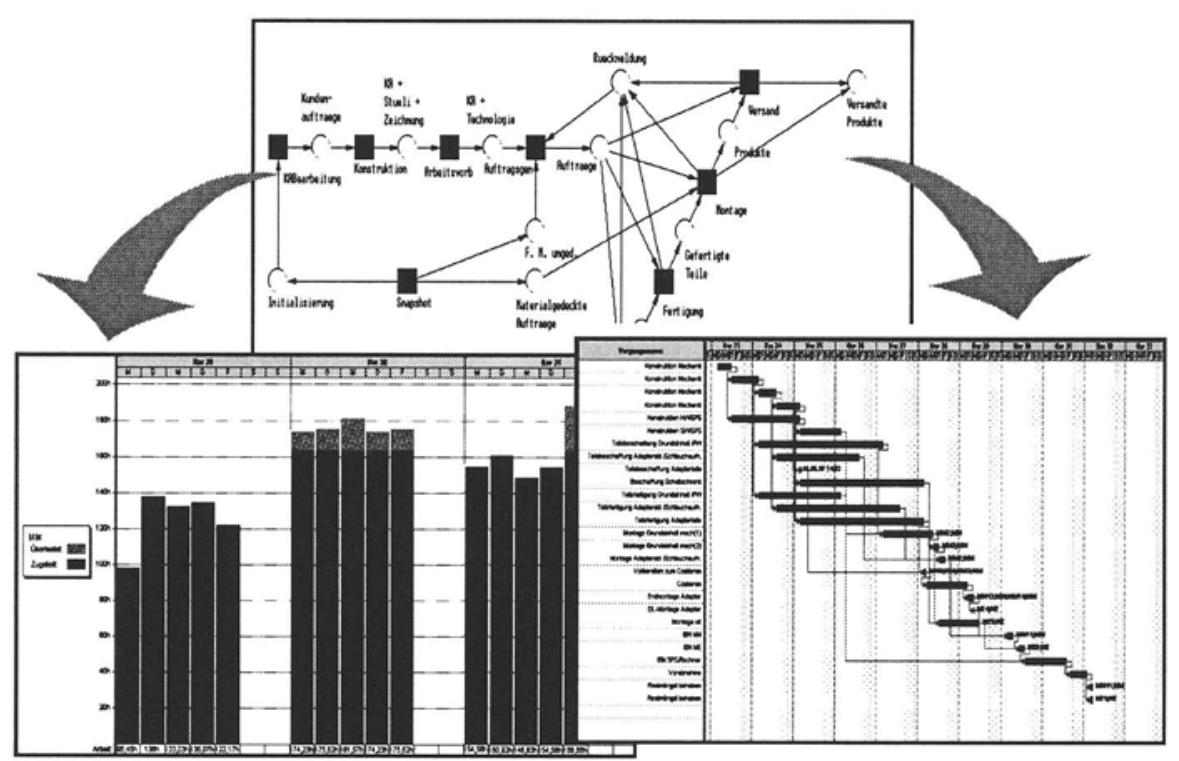

Figure 1 Results of simulation investigation

Simulating an order with the aid of a production system makes it possible to determine both time requirements and resource utilisation simultaneously. This task realisation is defined in a specific timeframe. In turn, resource consumption determines the cost of production and the capital lock-up in the previously defined timeframe. The simulation can then be used in aiding production preparation and implementation.

\section{CONCEPT OF DECISION-MAKING AIDS FOR INTEGRATED PROCESSES}

Despite the data resulting from the production process simulation, there is no guarantee for optimal results nor for the plans developed from them. In general, the solution in an actual situation is ambiguous and production scheduling is merely verified in compliance to the previous restrictions.

The question of an optimal process demands a close examination of the problem. Determining process quality serves as the starting point for such examinations. "Process quality" is defined as the characteristics of the value-added process which refer to the process's suitability to fulfil the given requirements (enterprise goals) as defined by the quality terminology in DIN 55350 (1987).

The requirements on the value-added process (initiated to fulfil customers' demands) are derived from the common goal of enterprises everywhere to maximise operational efficiency and is followed with a set of supplementary 
targets that are can be put into operation. Zäpfel (1996) subdivides this into intrafirm variables of resources, process efficiency, and capacity utilisation and into external (i.e., market-oriented) variables of supplier dependability, product quality, and processing time.

In favourable cases, these variables work complementarily or at least neutrally to one another. However, they often compete against each other and thus an optimum for each can not be simultaneously achieved. While reaching individual targets is easy, all previous attempts to describe an analytical procedure to determine the overall optimality of the combined targets have resulted with nothing.

Instead, determining and monitoring capacity utilisation, inventory, processing times, and deadline dependability/ delivery-readiness ratios (as described by Wiendahl (1991)) are sufficiently regarded as management tasks.

Concentrating on individual targets has been the predominant focus of research. However, to influence process quality as an expression of all the factors specifically, an integrated multi-criteria assessment of all targets should be done. For this, it is necessary to introduce a common assessment standard which could consider cost, time, and quality aspects.

The process quality control loop represented in Figure 2 is based on a real process replication in which the resulting data are introduced into a simulation model suitable for experimentation. From this, measurements can be attained and formed into a constant, thus allowing an assessment of a defined target in the overall goal system.

\footnotetext{
"The original standard uses "Process Efficiency" as a standard (e.g., stability, suitability, and disturbance-free operation of technical process. The term "Process efficiency" has been used here to avoid confusion.
} 


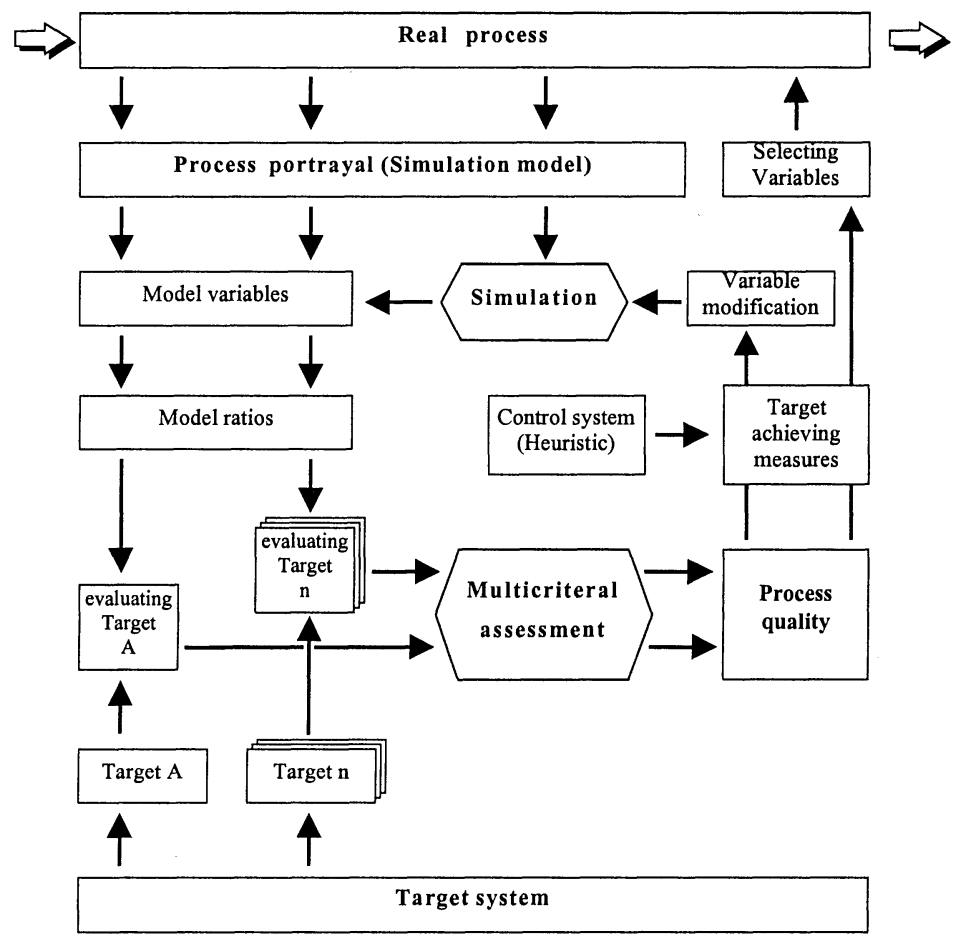

Figure 2 Control loop

A fundamental understanding of the cause-effect relationship between influential factors and the costs of the target achieving measures (control decisions) is necessary to be able to select and quantify goal-oriented measures when unsatisfactory results occur. The information required for this is prepared in a rule system which consists of universally applicable knowledge of the area of investigation on one side, and on the other side of the results of expert consultation and problem discussion on the part of the enterprises.

While the rule system depicts both positive (goal-oriented) as well as negative (goal-impeding) influences relating to individual targets, it does often take their antagonistic relationships into consideration.

Due to the considerable amount of uncertainty regarding the effectiveness and influence of individual target achieving measures and obvious impossibilities, the simulation must re-examine the influence of the resulting data on the real process. This allows all effects, desired and undesired, in the rule system to be collected. By testing solution alternatives at regular intervals, the simulation simultaneously indicates a favourable variant which then is implemented as a real process controlling directive.

A future enhancement of the principle presented here is that the results of the simulation run and its feedback from the real process can expand the rule system to include new recognisable patterns of interrelations between results. For example, 
the corrections necessary for the original, subjective, fixed parameters (such as influence factor and operation costs) to be assessed. In the course of time, the complete system's "ability to learn" should lead to fewer and fewer, but therefore better, solution alternatives being generated. Thus the cycle period is considerably shortened and a truly time-oriented system is created.

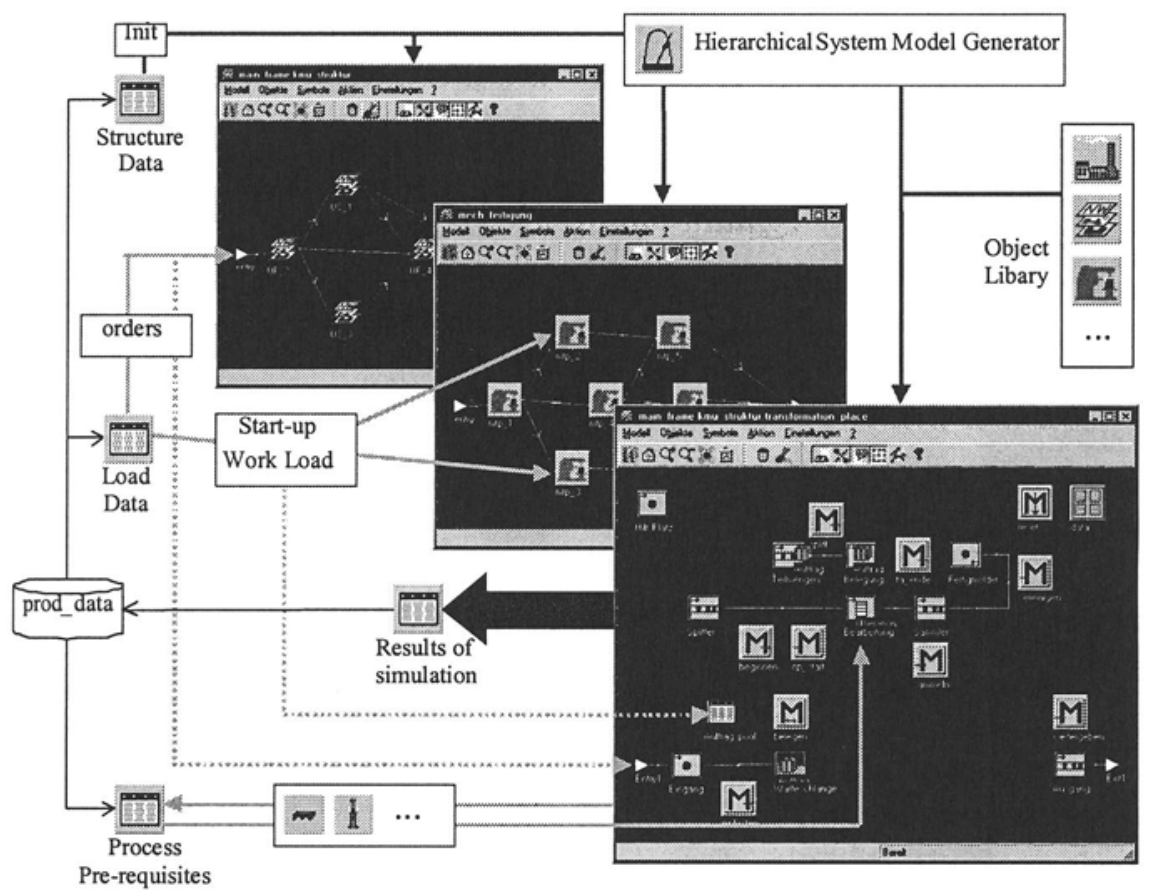

Figure 3 Base model of investigation systems

A sensible examination of such interrelations can only be accomplished by developing an active model, in which optimisation investigations can be carried out. Figure 3 represents a simulation model, which further describes a starting method for the solution process. 


\section{EXPANDING THE DECISION-MAKING SCOPE FOR PROCESS OPTIMISATION}

This enhanced model basis, however, still does not take into consideration all combinations and influence factors necessary to achieve an optimal process. In Figure 2, the logistical components of production processes were exclusively labelled as the individual targets which determine process quality. It should be noted that negligible feedback between the available resources and the production costs stemming from processing the order is not included. As a result, it is generally agreed upon that a production facility running at full capacity will quote higher prices than a facility with spare capacity (this also considers concrete enterprise decisions). However in such cases, the question as to how high the production costs (e.g., necessary contribution margin) are not too ambiguous to answer.

This point of view is based on the fact that essential fixed costs in a production facility are available at the latest in the medium-term. Included here are surface costs and their resulting costs such as heating, lighting, cleaning, etc. as well as depreciation adjustment costs and to a considerable extent, personnel costs. A model for optimising process resources must initially consider the influence of the strain of resources on production costs.

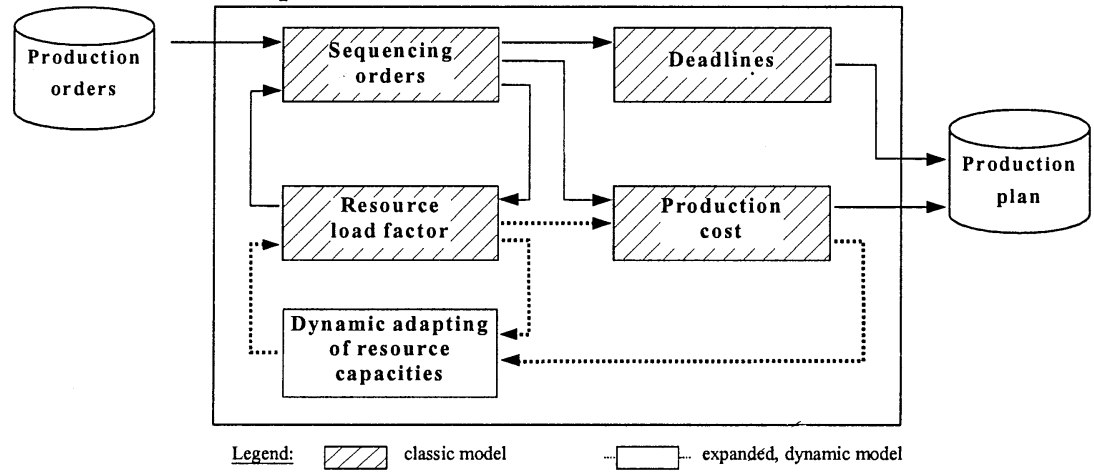

Figure 4 Dependencies and interactions in planning

Additionally, the question remains as to how far resources need not be considered a constant parameter. In concrete situations, they may be thought of as a variable that can be influenced. To a significant extent this is plausible in the case of personnel resources. Aspects of creating more flexible working hours do not only influence deadlines of overall production in such models, but also the resulting cost situation. Figure 4 schematically demonstrates this interaction and the problems of a complete optimum with regard to planning production and enterprise process.

While dynamically adapting resource capacity primarily offers promising approaches for optimising personal resources in individual enterprises, it can be 
broadened to networks of enterprises. The product and/ or process-dependant expansion and restriction result in the positive effects described above. Furthermore, creating process chains from such optimisation is easy (at least from a technical point of view) and corresponds to the root idea of operating a virtual network of enterprises. The problem can be certainly solved by an exhaustive optimisation process.

For this purpose, evolutionary and genetic algorithms may be used. The first investigations in this direction have yielded encouraging solution approaches. They were achieved on the basis of the Moduls Simple++_GA (Genetic Algorithm). The structures presented in Figures 2 and 4 can thus be supplied with a mathematically oriented solution.

\section{SUMMARY}

Deciding an applicable optimal process requires that enterprises use complex, integrated systems to clarify their decisions. Enterprises should not only strive to improve individual targets in operational efficiency, rather they should try to achieve a complete higher process quality. This can be achieved by the use of optimising simulation processes. On this bases it is then also possible to include further degrees of freedom, particularly by using dynamic resources in the search for optimal decisions.

\section{REFERENCES}

DIN 55350 Teil 11 (1987) Begriffe der Qualitätssicherung und Statistik. Berlin. Kernler (1996) PPS - Controlling, 35. Gabler - Verlag, Wiesbaden.

Petermann, Riedel, Reinicke (1998) Optimale Kooperationen in Unternehmennetzten durch Anwendung Genetischer Algorithmen. Zeitschrift für wirtschaftliche Fabrikbetrieb 937

Wiendahl, H.P. (1991) PPS - Anwendung der Belastungsorientierten Fertigungssteuerung. Munich

Zäpfel, G. Piekarz, B. (1996) Supply Chain Controlling. Wirtschaftsverlag C. Ueberreuter, Vienna

\section{BIOGRAPHY}

Prof. Dr. Joachim Petermann studied Machine Tool Design in Karl-Marx-Stadt (now Chemnitz) and graduated as a certified engineer in 1961. While working as an assistant and senior assistant in the fields of Electronics and Control Systems, he received his doctorate in 1976. Prof. Petermann worked several years in a research centre for the machine tool industry and received his second doctorate (Habilitation) in 1967. Since 1988 he has been employed at the Chemnitz 
University of Technology, first as a Lecturer for Process Automation and then, since 1992, as a full professor of Production Process Control and Factory Automation.

Prof. Dr. Siegfried Wirth studied Mechanical Engineering in Karl-Marx-Stadt (now Chemnitz) and graduated as a certified engineer. Working as an assistant and senior assistant, he received his doctorate in 1967. After working for several years in industry as a project leader and industrial and technological planner, he was appointed to the position of college instructor for 1971/72 study year. In 1975 he received his second doctorate (Habilitation) at the Technical University of Dresden. Since 1978 he has been a full professor of Technological Plant Planning at the Technical College of Karl-Marx-Stadt (now Chemnitz University of Technology), where he also became a Level C 4 Professor of Factory Planning and Factory Management in 1992. 